\title{
Nursing Effect of Zinc Oxide Nanoantibacterial Materials after Adrenalectomy
}

\author{
Yiyang Fan, ${ }^{1}$ Jingjing Liu, ${ }^{2}$ and Mingrui Fan $\mathbb{D}^{3}$ \\ ${ }^{1}$ Department of Urology, First People's Hospital of Chenzhou City, Chenzhou, 423000 Hunan, China \\ ${ }^{2}$ Department of Oncology, Third Xiangya Hospital, Central South University, Changsha, 410006 Hunan, China \\ ${ }^{3}$ Department of Psychological Rehabilitation, First People's Hospital of Zixing City, Chenzhou, 423000 Hunan, China
}

Correspondence should be addressed to Mingrui Fan; rfvbgt1128@tom.com

Received 30 December 2021; Revised 18 January 2022; Accepted 26 January 2022; Published 7 March 2022

Academic Editor: Palanivel Velmurugan

Copyright (c) 2022 Yiyang Fan et al. This is an open access article distributed under the Creative Commons Attribution License, which permits unrestricted use, distribution, and reproduction in any medium, provided the original work is properly cited.

Laparoscopic adrenalectomy (RLA) is widely used for adrenal tumors, cancer, cortical hyperplasia, etc. Therefore, how to care for patients after surgery is a necessary means to speed up the rapid healing of surgical wounds and reduce the incidence of related complications. To solve the problem in traditional wound treatment, antibacterial dressings are used, and most of the auxiliary materials need to be replaced frequently, or there is serious adhesion to the wound, which causes secondary wound infection. The methods used to study in this work report a new long-acting antibacterial and breathable wound dressing based on nanoscale zinc oxide nanoparticles ( $\mathrm{ZnO} \mathrm{NPs}$ ) in the care of adrenalectomy; the clinical effects of ZnO NP-based antibacterial dressings were systematically evaluated in terms of patients' wound healing rate (\%), infection rate (\%), healing time (d), and the number of dressing changes. The results revealed that the wound healing rate of patients with ZnO NP-based antibacterial dressing was as high as $16.67 \%$ and the incidence of adverse reactions was only $26.19 \%$, which was $40.48 \%$ lower than traditional dressings. Such promising antibacterial dressings are expected to be greatly used in the medical field in the future.

\section{Introduction}

The main purpose of any surgical treatment is to complete the resection of the lesion and wound healing as quickly as possible to avoid infection. Minimally invasive RLA also inevitably leaves a wound, and the slow healing process of the wound is the accumulation area of high infectious inflammatory load $[1,2]$. The factors that increase the delay of wound healing mainly involve the formation of microbial complexes, types, and biofilms at the wound, but they are not limited to these factors. The main microorganisms concentrated on the wound surface are Pseudomonas, Staphylococcus, Streptococcus, etc., which have been confirmed by various microbiological methods and microbial spectrum. These microbial populations show increasingly strong resistance to traditional antibacterial dressings. Therefore, new antibacterial dressings are waiting to be developed to relieve the distress of postoperative wound care for patients [3].

Nanograde zinc oxide nanoparticles (ZnO NPs) belong to the white hexagonal crystal system, with a particle size distribution in the range of $1.00-100 \mathrm{~nm}$. It has extremely high chemical, catalytic, and photocatalytic activities [4]. In addition, $\mathrm{ZnO}$ NPs have antibacterial functions similar to ultraviolet rays and are widely used in antibacterial drugs, dressings, test papers, and other fields [5]. Antibacterial compounds such as silver sulfadiazine and silver nitrate developed in modern times enjoy the reputation of the "gold standard" in the treatment of inflammatory wounds. However, these antibacterial compounds are slow in accelerating the wound healing process, have obvious cytotoxic effects on host cells, and easily leave scars. Compared with these classic antibacterial compounds, the novel ZnO NPs exhibit excellent antibacterial function at an appropriate concentration and do not have any side effects on normal cells, which have been confirmed by many experiments [6]. $\mathrm{Zn}^{2+}$ particles are released through $\mathrm{ZnO} \mathrm{NP}$ cell mediator to promote the formation of keratin and recruit repair cells to gather at the wound, thereby speeding up wound healing [7-9].

The optimum dressing should be flexible, mechanically strong, tear-resistant, and porous $[10,11]$. It should also be 
able to adequately absorb extravasated fluid from the wound surface without sticking to it [12]. The antibacterial dressing must also block external germs and prevent their development and reproduction on the wound surface. The antimicrobial dressing must be permeable to allow gas exchange with the outside environment to promote wound healing cell proliferation [13-15]. Because of this, polyvinyl alcohol (PVA), which has good biocompatibility, bioadhesion, and nontoxicity, was chosen as the coating material for the $\mathrm{ZnO} \mathrm{NP}$ antibacterial agent in this study in order to comply with the demanding standards of medical antibacterial dressings. The chemical response of PVA can be modified by modifying its simple chemical structure, which is based on its basic chemical structure. It is surprising to learn that, aside from its rubber-like qualities (viscoelasticity), PVA exhibits a high degree of swelling in either water or biological fluids, which allows it to mimic real tissues and be adequately tolerated by the human body $[16,17]$.

Bacterial cellulose (BC) is a porous network nanoscale biopolymer synthesized by microbial fermentation. Because of its excellent biocompatibility, adaptability, and biodegradability, it is possible to construct a new type of wound medical dressing $[18,19]$. BC is usually a polysaccharide polymer synthesized by bacteria such as Acetobacter, Gluconobacter, Oomycetes, Agrobacterium, Sarcobacteria, and Enterobacter [20]. As far as we know, the study of $\mathrm{ZnO}$ NPs in BC and PVA composite gel medical antibacterial dressings has not been reported, and some related studies only consider a single influencing factor and lead to inevitable defects. For example, Wahid et al. [21] only emphasized the antibacterial properties of the $\mathrm{BC} / \mathrm{ZnO}$ nanocomposite film, but the cytotoxicity of the dressing in the actual application process was not considered in depth. Therefore, when designing wound antibacterial dressings, one should not blindly pursue antibacterial effects. It is necessary to balance the antibacterial properties and potential cytotoxicity of wound dressings from the overall perspective.

Surgical therapy is aimed at removing the lesion and encouraging wound healing as early as possible to prevent infection. The cytotoxicity of the dressing during application was not extensively evaluated prior to the operation. When making antibacterial wound dressings, keep in mind that antibacterial characteristics are not the primary consideration.

This work systematically explores the reasonable ratio of antibacterial gel dressings ( $\mathrm{ZnO}-\mathrm{BC} / \mathrm{PVA})$ for postadrenalectomy wound care based on $\mathrm{BC}$ and PVA polymer composite network coated with $\mathrm{ZnO} \mathrm{NPs}$, aiming to improve the antibacterial performance of the dressing at the same time; it reduces its potential toxic effect on cells, thereby constructing a new type of air-permeable wound surface antibacterial care dressing and exploring its actual care effect in clinical applications.

\section{Materials and Methods}

2.1. Reagent. Zinc oxide nanoparticles ( $\mathrm{ZnO} \mathrm{NPs}$, average size: $50 \pm 10 \mathrm{~nm}$ ) and polyvinyl alcohol (PVA, alcoholysis degree: $98.0-99.0 \mathrm{~mol} \%$, viscosity: $3.2-3.8 \mathrm{mPa} \cdot \mathrm{s}$ ) were purchased from Sigma-Aldrich (St. Louis, Missouri, United
States). Bacterial cellulose (BC, gel state, about 50-100 nm in diameter, $20 \mu \mathrm{m}$ in length) was provided by Shanghai Guangyu Biotechnology Co., Ltd. (Shanghai, China). Sodium periodate $\left(\mathrm{NaIO}_{4}, 99.0 \%\right)$, ethylene glycol $\left(\mathrm{C}_{2} \mathrm{H}_{6} \mathrm{O}_{2}, 99.5 \%\right)$, zinc chloride $\left(\mathrm{ZnCl}_{2}, 99.0 \%\right)$, and sodium hydroxide $(\mathrm{NaOH}, 99.9 \%)$ were purchased from Shanghai Chemical Reagent Co., Ltd. (Shanghai, China).

2.2. Instrument. The surface morphology and microstructure of $\mathrm{ZnO}$-BC/PVA were observed by a scanning electron microscope (SEM, JSM-6701F, Japan). Purified water equipment (UPH-I-5, UPH Instrument Equipment Co., Ltd., Shaanxi, China) is used to produce deionized water. All experiments use deionized water as the solvent, and all reagents can be used without further purification.

2.3. $\mathrm{ZnO}-\mathrm{BC} / \mathrm{PVA}$ Preparation. The antibacterial gel $\mathrm{ZnO}$ $\mathrm{BC} / \mathrm{PVA}$ was prepared based on a three-step method. Initially, $100 \mathrm{~g}$ of $\mathrm{BC}$ was dispersed in ultrapure water $(500 \mathrm{~mL})$ and stored at room temperature for $24 \mathrm{~h}$. Then, the $\mathrm{BC}$ gel was transferred to $0.10 \mathrm{M} \mathrm{NaOH}$ solution and soaked for $24 \mathrm{~h}$ to remove the remaining impurities in the $\mathrm{BC}$ gel. Wash the $\mathrm{BC}$ gel with ultrapure water several times until its $\mathrm{pH}=7.0$, and store it in a $4.0^{\circ} \mathrm{C}$ freezer for later use.

The above $\mathrm{BC}$ was dispersed in $\mathrm{NaIO}_{4}(1: 2 w / w)$, and the flask was wrapped in a tin foil to react for $12 \mathrm{~h}$ at $50^{\circ} \mathrm{C}$ in the dark. After the reaction was completed, $100 \mathrm{~mL}$ of $0.10 \mathrm{M} \mathrm{C}_{2} \mathrm{H}_{6} \mathrm{O}_{2}$ was added to the reaction system and the reaction continued for $2.0 \mathrm{~h}$. The obtained $\mathrm{BC}$ mixture was soaked in ultrapure water for $3.0 \mathrm{~h}$ to remove excess $\mathrm{NaIO}_{4}$ and $\mathrm{C}_{2} \mathrm{H}_{6} \mathrm{O}_{2}$. PVA was dissolved in distilled water at $80^{\circ} \mathrm{C}$ for about $6.0 \mathrm{~h}$ to obtain a $15.0 \%$ PVA dispersion, and then, the oxidized $\mathrm{BC}$ gel was placed in a $15.0 \%$ PVA solution and allowed to stand for $24 \mathrm{~h}$ to obtain a BC/PVA gel. Finally, the $\mathrm{BC} / \mathrm{PVA}$ was washed three times with ultrapure water to remove unreacted PVA.

Add $200 \mathrm{~mL}$ of $0.05 \mathrm{M} \mathrm{ZnCl}_{2}$ solution to the BC/PVA gel, and soak for $30 \mathrm{~h}$ at room temperature to obtain a $\mathrm{ZnO}-\mathrm{BC} / \mathrm{PVA}$ gel. Then, take out the gel and rinse it with pure water 3 times. Finally, the gel was soaked in $0.20 \mathrm{M}$ $\mathrm{NaOH}$ for $12 \mathrm{~h}$ and washed with pure water to $\mathrm{pH}=7.0$.

\subsection{Clinical Application of $\mathrm{ZnO}-\mathrm{BC} / \mathrm{PVA}$}

2.4.1. General Patient Information. Eighty-one patients undergoing adrenalectomy were selected, including 41 males and 40 females. The age distribution ranged from 31 to 62 years, and the disease course was in the distribution range of one to three years. The patients were randomly divided into two groups, namely, silver sulfadiazine (SS) and $\mathrm{ZnO}$ NP-based antibacterial dressing group (ZnO-BC/PVA). And the baseline data of each group of patients is recorded in Table 1.

2.4.2. Inclusion and Exclusion Criteria. The inclusion criteria for this work are as follows: the patient's cognitive function is normal, and there is no redness, swelling, or purulent discharge on the wound after adrenalectomy; the patient and his family are professionally trained and qualified for home treatment; the study adopts the principle of patient 
TABLE 1: General patient information.

\begin{tabular}{lcc}
\hline Project & $\begin{array}{c}\text { SS group } \\
(n=39)\end{array}$ & $\begin{array}{c}\text { ZnO-BC/PVA group } \\
(n=42)\end{array}$ \\
\hline Sex & & \\
$\quad$ Male & 23 & 24 \\
$\quad$ Female & 16 & 18 \\
Age (years) & $47.52 \pm 5.67$ & $48.29 \pm 4.82$ \\
Course of disease & $1.68 \pm 0.79$ & $1.74 \pm 0.83$ \\
(years) & & \\
Tumor diameter & $3.21 \pm 0.87$ & $3.19 \pm 0.74$ \\
(mm) & & \\
Disease site & 19 & 21 \\
$\quad$ Left & 20 & 21 \\
$\quad$ Right & & \\
\hline
\end{tabular}

voluntariness; all patients have signed informed consent. The exclusion criteria include patients with a history of infection in the recent (1.0-3 months) and other clinical trials; those with discomfort or allergies to ZnO NP-based antibacterial dressings; patients with critical illness; and the inability to evaluate drugs due to the use of other drugs. Effective patients can withdraw from this study when they have serious adverse reactions.

2.4.3. Nursing Plan. Disinfect the wounds of the two groups of patients, implement the corresponding medical antibacterial dressing treatment, and guide the patients to change the dressing operation (Figure 1). In addition, pay close attention to the patient's psychological state and wound healing, and provide timely guidance. Provide scientific guidance on diet, and urge patients to strengthen nutrition and eat high-calcium, high-vitamin, and high-protein foods to speed up wound healing. Record the bleeding, exudation, pain, and other conditions of the wounds of the two groups of patients, and take targeted treatment measures. For instance, when replacing the antibacterial dressing, use $0.50 \%$ povidone-iodine and normal saline to treat the wound repeatedly before changing the dressing. The frequency of dressing change between the two groups of patients was adjusted according to the severity of exudation and pain, and wound secretions were collected regularly for in vitro culture to identify bacteria accumulated on the wound and evaluate wound healing.

2.4.4. Measurement Index. After three weeks of antibacterial dressing treatment, the total effective rate, VSA score and nursing satisfaction of the two groups of patients were counted. Among them, the wound is fully healed and no scar is counted as healed; the wound with a reduction of $30.0 \%$ and a smaller scar is counted as significant; the wound with a reduction of $50 \%$ and scars is counted as effective; and the wound with a smaller reduction rate is counted as ineffective. The timeliness of the two dressings was evaluated by counting the number of dressing changes and the interval between patients, and the number of bacteria on the wounds of the two groups of patients was detected to evaluate the antibacterial properties of the dressings. Statistical analysis was made on the adverse reactions and complication rates of the two medical antibacterial dressings.

2.5. Statistical Methods. Use SPSS 22.0 to process, and analyze the data involved in this research. Quantitative variables are expressed as the mean \pm standard deviation $(\bar{x} \pm s)$, and qualitative variables are described by frequency distribution and percentage (\%). The $t$-test is used for the analysis of quantitative variables, and the analysis of qualitative variables uses the $\chi^{2}$ test. $P<0.05$ indicates statistical significance.

\section{Results and Discussion}

3.1. Morphological Characteristics of $\mathrm{ZnO}-\mathrm{BC} / \mathrm{PVA}$. SEM, as a promising characterization technology for material morphology research, can provide important information such as the shape and particle size of the material. The SEM morphology image of $\mathrm{ZnO}-\mathrm{BC} / \mathrm{PVA}$ is shown in Figure 2. On the one hand, adding $\mathrm{BC}$ to the PVA gel can form very fine pores at the communication between the two structures. And with the incorporation of $\mathrm{ZnO}$, the porosity further increases. On the other hand, lamellar and ravine cross-sections can be observed on the $\mathrm{ZnO}-\mathrm{BC} / \mathrm{PVA}$ gel film. The addition of $\mathrm{BC}$ reduces the original threedimensional polymer morphology of PVA, and the appearance of holes, cracks, and ravines appears. This result leads to a decrease in the degree of entanglement of PVA itself, resulting in an increase in the size of the relative entangled porous, thus breaking the original three-dimensional polymer morphology of PVA. From the PVA/BC cross-section, it is observed that the white light-emitting points are $\mathrm{ZnO}$ nanoparticles, which are firmly incorporated in the PVA/ $\mathrm{BC}$ matrix. According to the statistics of the distribution of $\mathrm{ZnO}$ nanoparticles, it is found that the distribution of $\mathrm{ZnO}$ nanoparticles in the PVA/BC matrix is relatively uniform. The increased $\mathrm{ZnO}$ nanoparticles reduce the effect of $\mathrm{BC}$ induced PVA pore enlargement, which is attributed to the van der Waals force between $\mathrm{ZnO}$ nanoparticles and $\mathrm{BC}$, which can make $\mathrm{ZnO}-\mathrm{BC} / \mathrm{PVA}$ to pack tightly and reduce the system ability.

3.2. Pain Assessment and VAS Score. We aim to further clarify the effect of $\mathrm{ZnO}-\mathrm{BC} / \mathrm{PVA}$ antibacterial dressing in the actual experience of patients and to investigate whether it has analgesic effect on patients' wounds. By applying the antibacterial dressing $\mathrm{ZnO}-\mathrm{BC} / \mathrm{PVA}$ to the surgical wounds of patients undergoing PLA and at the same time recording the changes in the patient's wound pain index before and 1, 2 , and 3 weeks after the care of the patient, it is used to evaluate the analgesic effect of the new antibacterial material. The results are displayed in Figure 3. The pain scoring standard is assessed by the visual analog scale (VAS), where zero points represents no pain and ten points represents severe pain. Statistical analysis shows that patients who use the new $\mathrm{ZnO}$-BC/PVA antibacterial dressing and those who use traditional silver sulfadiazine have similar low pain, which further shows that $\mathrm{ZnO}-\mathrm{BC} / \mathrm{PVA}$ can reduce the postoperative wound surface while relieving antibacterial pain. 


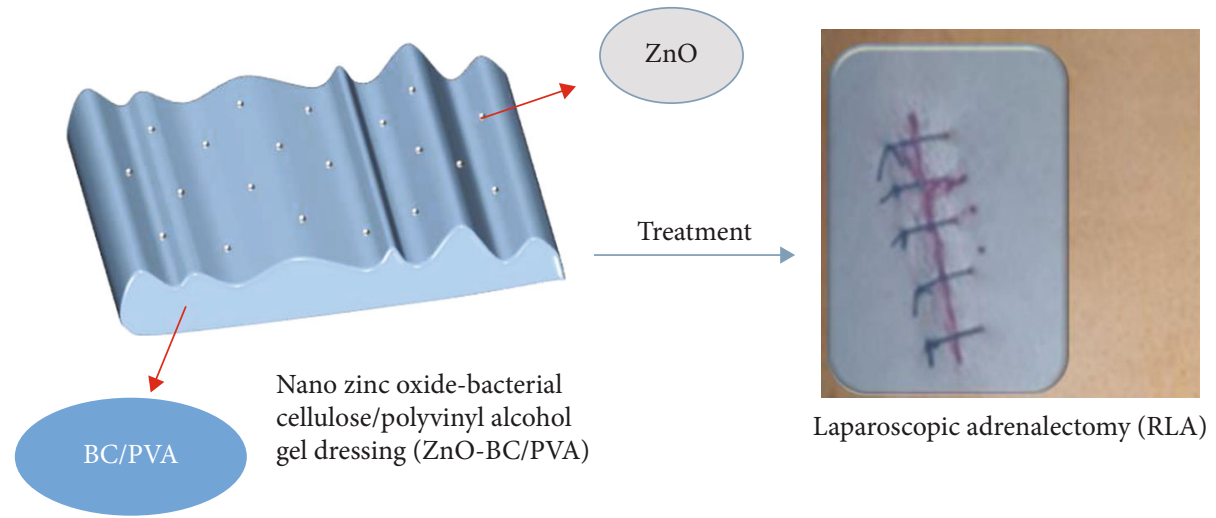

FIgURE 1: Application of ZnO-BC/PVA antibacterial nursing dressing in nursing after adrenalectomy.

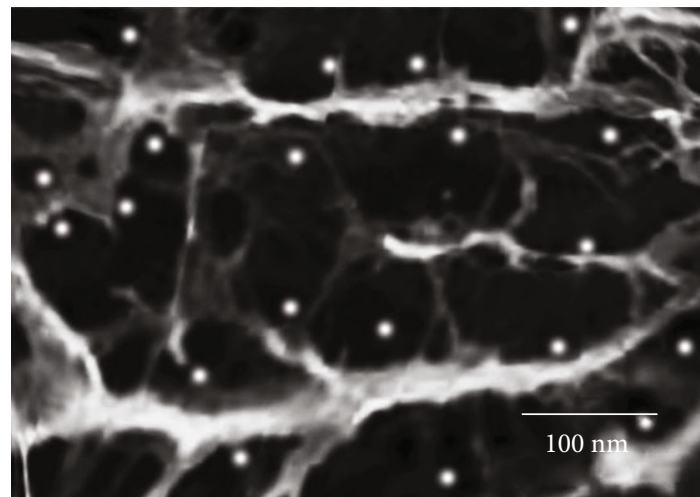

Figure 2: Characterization of the morphology of zinc oxidebacterial cellulose/polyvinyl alcohol (ZnO-BC/PVA).

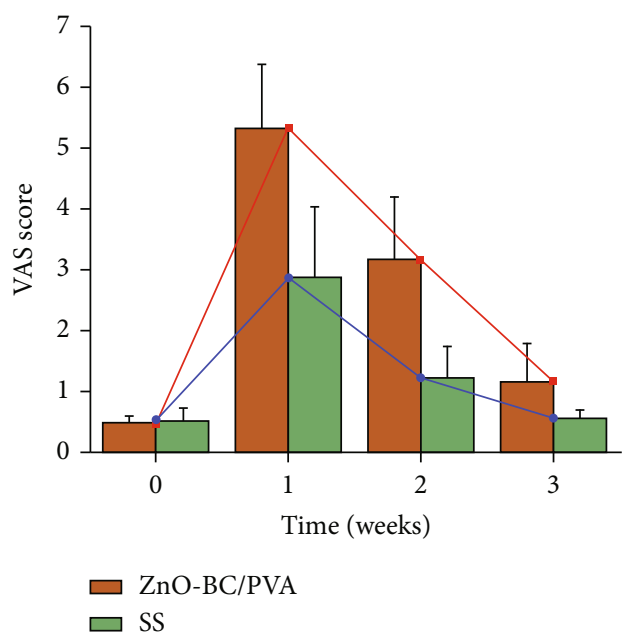

FIGURE 3: Comparison of the analgesic ability of zinc oxidebacterial cellulose/polyvinyl alcohol (ZnO-BC/PVA) and silver sulfadiazine (SS).

3.3. Wound Healing Rate. Figure 4 shows the effect of $\mathrm{ZnO}-$ $\mathrm{BC} / \mathrm{PVA}$ antibacterial dressing on wound healing after three weeks. Statistics found that the healing rate of patients in the $\mathrm{ZnO}-\mathrm{BC} / \mathrm{PVA}$ group (16.67\%) was significantly higher than that of the SS group (7.69\%). In addition, the number of invalid patients is small, which proves that compared with the SS group, $\mathrm{ZnO}-\mathrm{BC} / \mathrm{PVA}$ antibacterial dressing has a better nursing effect after adrenalectomy.

3.4. Interval between Dressing Changes. After the dressing is used for a period of time, a new dressing needs to be replaced. However, frequent dressing changes will expose the wound to the air, which will increase the number of bacteria on the wound. In order to prevent wound infections in patients, the number of dressing changes in the nursing process should be minimized. Increase the interval between dressing changes. Figure 5 shows the average time between dressing changes for patients in three weeks. Statistical analysis showed that $48.0 \%$ of the patients in the $\mathrm{ZnO}-\mathrm{BC} / \mathrm{PVA}$ group had a dressing change interval of more than $72 \mathrm{~h}$. Compared with the SS group, the dressing change interval was significantly increased $(P<0.05)$.

3.5. Bacteria Detection Rate on Wound. In order to further research the anti-infection ability of $\mathrm{ZnO}-\mathrm{BC} / \mathrm{PVA}$ dressings, the detection rate of bacteria on the wound surface was tested every three days, and the results are recorded in Figure 6 . With the increase of time, the detection rate of bacteria on the wounds of patients showed a declining trend. And compared with the SS group, the detection rate of $\mathrm{ZnO}$ BC/PVA bacteria decreased faster, and only $4.36 \pm 1.23$ was detected at 21 days, while in the SS group it was $26.81 \pm 1.54$ $\%$. This result proves that $\mathrm{ZnO}-\mathrm{BC} / \mathrm{PVA}$ dressing can significantly reduce the bacterial content of wounds and reduce the possibility of patient infection.

3.6. Adverse Reaction Rate. Wound infection, bleeding, shock, and other adverse reactions often occur in nursing after adrenalectomy. Figure 7 shows the occurrence of adverse reactions during the nursing process of the $\mathrm{ZnO}$ $\mathrm{BC} / \mathrm{PVA}$ group and the SS group. According to statistical analysis, the incidence of adverse reactions in the $\mathrm{ZnO}-\mathrm{BC} /$ PVA group was low, and there were no serious adverse reactions such as shock. It shows that $\mathrm{ZnO}-\mathrm{BC} / \mathrm{PVA}$ can significantly reduce the occurrence of adverse reactions in postoperative care. 


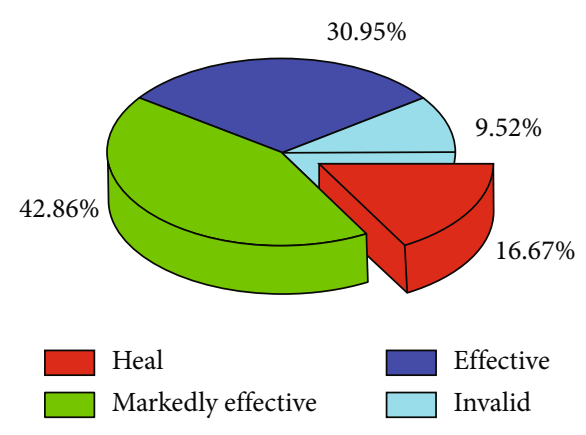

(a)

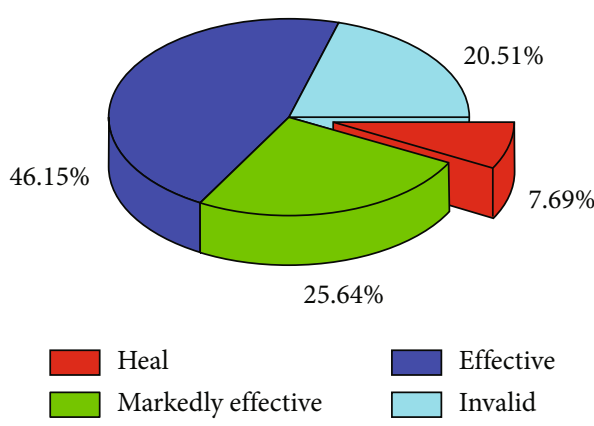

(b)

FIgURE 4: Comparison of the wound healing ability of zinc oxide-bacterial cellulose/polyvinyl alcohol (ZnO-BC/PVA) and silver sulfadiazine (SS).

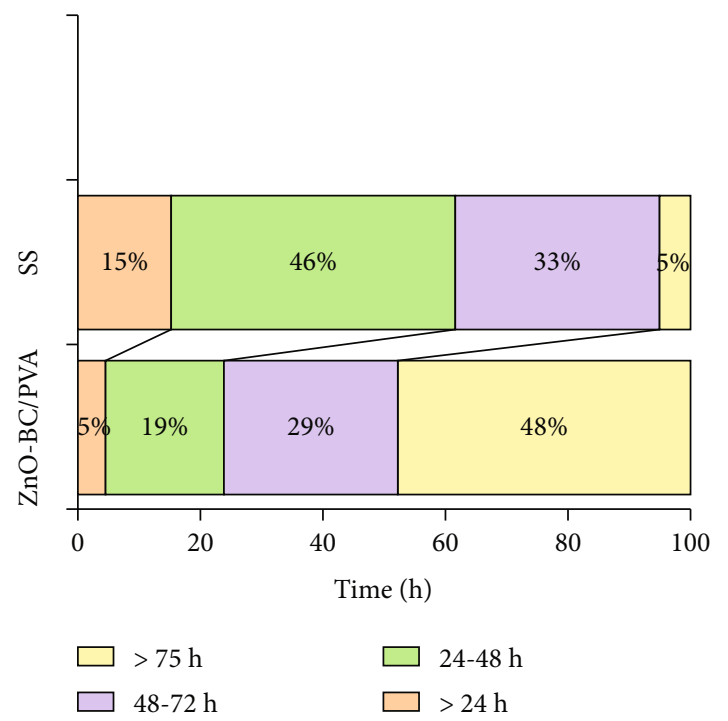

FIGURE 5: Comparison of dressing change intervals between zinc oxide-bacterial cellulose/polyvinyl alcohol ( $\mathrm{ZnO}-\mathrm{BC} / \mathrm{PVA}$ ) and silver sulfadiazine (SS).

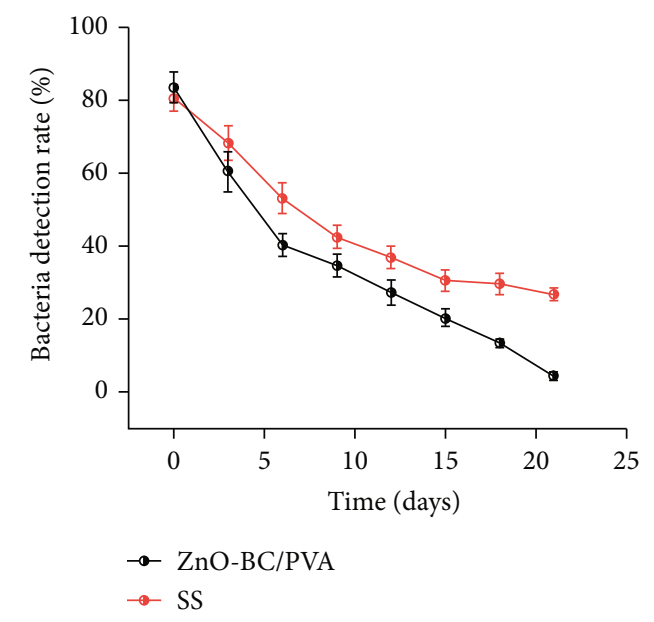

Figure 6: Comparison of the detection rate of wound bacteria between zinc oxide-bacterial cellulose/polyvinyl alcohol (ZnO-BC/ PVA) and silver sulfadiazine (SS).

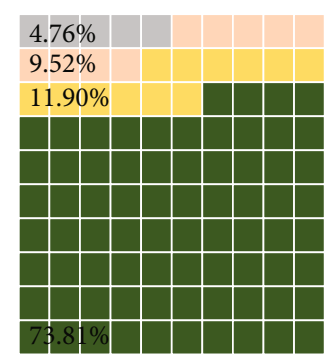

$\mathrm{ZnO}-\mathrm{BC} / \mathrm{PVA}$

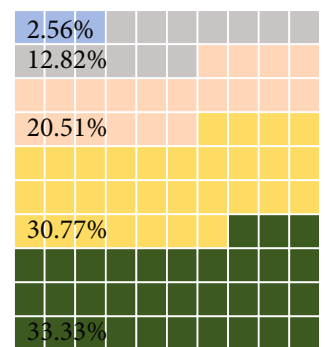

SS

$$
\begin{aligned}
& \text { Shock } \\
& \text { Bleeding } \\
& \text { Wound infection } \\
& \text { Other adverse reactions } \\
& \text { No adverse reactions }
\end{aligned}
$$

(b)
FIGURE 7: The incidence of adverse reactions between zinc oxidebacterial cellulose/polyvinyl alcohol ( $\mathrm{ZnO}-\mathrm{BC} / \mathrm{PVA}$ ) and silver sulfadiazine (SS). (a) ZnO-BC/PVA. (b) SS.

\section{Discussion}

RLA has been widely used in clinical practice, but it is prone to wound infection, bleeding, and even shock during postoperative care [22]. Dressings are considered to be an important method to promote wound healing and prevent bacterial infections [23]. The ideal dressing should have multiple properties such as flexibility, porosity, anti-infection, and high swelling properties [24]. PVA is a watersoluble polymer with a simple chemical structure and can be chemically modified through some simple reactions $[25$, 26]. Meanwhile, PVA gel also has a high degree of swelling, which is a good dressing carrier [27]. In addition, $\mathrm{ZnO}$ NPs, as a safe and nontoxic metal oxide nanomaterial, are widely used in the biomedical field because of their antibacterial, antioxidant, and anticancer properties [28, 29]. Based on the antibacterial activity of ZnO NPs, Bharathi and Bhuvaneshwari [30] developed a safer and more environmentally friendly synthesis method for $\mathrm{ZnO}$ NPs. At the same time, they proved that ZnO NPs have good antibacterial, antioxidant, and antibreast cancer cell proliferation effects, and can be used as a powerful bactericide. 
In summary, this work prepared a new long-acting antibacterial and breathable wound dressing $\mathrm{ZnO}-\mathrm{BC} / \mathrm{PVA}$ based on $\mathrm{ZnO}$ NPs. The characterization results showed that the $\mathrm{ZnO}-\mathrm{BC} / \mathrm{PVA}$ antibacterial dressing has a compact porous structure. The particles are relatively evenly distributed in the PVA/BC matrix, which is suitable for clinical application as a dressing. In clinical trials, the $\mathrm{ZnO}-\mathrm{BC} /$ PVA dressing showed good antibacterial properties, and its anti-infection ability was stronger than traditional dressings. At the same time, in the 21-day treatment, $\mathrm{ZnO}-\mathrm{BC} / \mathrm{PVA}$ dressing can effectively promote wound healing, extend the interval between dressing changes, reduce the pain of the patient, and significantly reduce the incidence of postoperative complications. Therefore, the $\mathrm{ZnO}-\mathrm{BC} / \mathrm{PVA}$ material synthesized in this research can be used as an antibacterial dressing in clinical nursing after adrenalectomy.

\section{Conclusion}

The study contributed a $\mathrm{ZnO}-\mathrm{BC} / \mathrm{PVA}$ antibacterial gel dressing for wound care after adrenalectomy was constructed based on BC and PVA polymer composite network coated with $\mathrm{ZnO}$ NPs. It possesses antibacterial, analgesic, and anti-infection properties. It can also speed up wound healing and decrease problems. This study offers a new clinical alternative following adrenalectomy.

\section{Data Availability}

The data underlying the results presented in the study are available within the manuscript.

\section{Ethical Approval}

Research experiments conducted in this article with humans were approved by the Medical Ethics Committee of Cangzhou Central Hospital following all guidelines, regulations, legal, and ethical standards as required for humans.

\section{Conflicts of Interest}

There are no conflicts to declare.

\section{Acknowledgments}

We gratefully appreciate the colleagues and the experimental staff at Cangzhou Central Hospital for providing the equipment.

\section{References}

[1] C. Withycombe, K. J. Purdy, and S. E. Maddocks, "Micromanagement: curbing chronic wound infection," Molecular Oral Microbiology, vol. 32, no. 4, pp. 263-274, 2017.

[2] K. S. Sandeep, K. S. Ajay, G. Vanya, K. Aman, and S. Priyanka, "Challenges with wound infection models in drug development," Current Drug Targets, vol. 21, no. 13, pp. 1301-1312, 2020.
[3] Z. W. Li and K. Menno, "Antibacterial strategies for wound dressing: preventing infection and stimulating healing," Current Pharmaceutical Design, vol. 24, no. 8, pp. 936-951, 2018.

[4] M. Saravanan, S. Dhivakar, and S. Jayanthi, "An eco friendly and solvent free method for the synthesis of zinc oxide nano particles using glycerol as organic dispersant," Materials Letters, vol. 67, no. 1, pp. 128-130, 2012.

[5] A. A. Alswat, M. B. Ahmad, T. A. Saleh, M. Z. B. Hussein, and N. A. Ibrahim, "Effect of zinc oxide amounts on the properties and antibacterial activities of zeolite/zinc oxide nanocomposite," Materials Science and Engineering, vol. 68, pp. 505-511, 2016.

[6] S. W. T. Chew, Y. Zeng, M. Cui et al., "In situ generation of zinc oxide nanobushes on microneedles as antibacterial coating," SLAS Technology, vol. 24, no. 2, pp. 181-187, 2019.

[7] C. B. Thompson, T. L. Wiemken, and T. S. Brown, "Effect of postoperative dressing on excisions performed on the leg: a comparison between zinc oxide compression dressings versus standard wound care," Dermatologic Surgery, vol. 43, no. 11, pp. 1379-1384, 2017.

[8] S. Majumder, U. Ranjan Dahiya, S. Yadav et al., "Zinc oxide nanoparticles functionalized on hydrogel grafted silk fibroin fabrics as efficient composite dressing," Biomolecules, vol. 10, no. 5, pp. 710-710, 2020.

[9] Z. Hadisi, M. Farokhi, H. R. Bakhsheshi-Rad et al., "Hyaluronic acid HA-based silk fibroin/zinc oxide core-shell electrospun dressing for burn wound management," Macromolecular Bioscience, vol. 20, no. 4, pp. 19003281900328(17), 2020.

[10] M. E. Aljghami, S. Saboor, and S. Amini-Nik, "Emerging innovative wound dressings," Annals of Biomedical Engineering, vol. 47, no. 3, pp. 659-675, 2019.

[11] G. Mihaela, C. C. Mariana, M. Luminita et al., "Bioactive wound dressings for the management of chronic wounds," Current Organic Chemistry, vol. 21, no. 1, pp. 53-63, 2016.

[12] S. Homaeigohar and A. R. Boccaccini, "Antibacterial biohybrid nanofibers for wound dressings," Acta Biomaterialia, vol. 107, pp. 25-49, 2020.

[13] D. Kowalczuk, M. Miazga-Karska, A. Gładysz, P. Warda, A. Barańska, and B. Drop, "Characterization of ciprofloxacin-bismuth-loaded antibacterial wound dressing," Molecules, vol. 25, no. 21, pp. 5096-5096(13), 2020.

[14] A. Bal-Öztürk, B. Özkahraman, Z. Özbaş, G. Yaşayan, E. Tamahkar, and E. Alarçin, "Advancements and future directions in the antibacterial wound dressings - a review," Journal of Biomedical Materials Research Part B: Applied Biomaterials, vol. 109, no. 5, pp. 703-716, 2021.

[15] L. M. Ge, Y. B. Xu, X. Y. Li et al., "Fabrication of antibacterial collagen-based composite wound dressing," ACS Sustainable Chemistry \& Engineering, vol. 6, no. 7, pp. 9153-9166, 2018.

[16] Z. W. Abdullah, Y. Dong, I. J. Davies, and S. Barbhuiya, "PVA, PVA blends, and their nanocomposites for biodegradable packaging application," Polymer-Plastics Technology and Engineering, vol. 56, no. 12, pp. 1307-1344, 2017.

[17] J. Zanela, M. Casagrande, M. O. Reis, M. V. E. Grossmann, and F. Yamashita, "Biodegradable sheets of starch/polyvinyl alcohol PVA: effects of PVA molecular weight and hydrolysis degree," Waste and Biomass Valorization, vol. 10, no. 2, pp. 319-326, 2019.

[18] C. S. Ruan, Y. J. Zhu, X. Zhou, N. Abidi, Y. Hu, and J. M. Catchmark, "Effect of cellulose crystallinity on bacterial cellulose assembly," Cellulose, vol. 23, no. 6, pp. 3417-3427, 2016. 
[19] H. Q. Yan, X. Q. Chen, H. W. Song et al., "Synthesis of bacterial cellulose and bacterial cellulose nanocrystals for their applications in the stabilization of olive oil Pickering emulsion," Food Hydrocolloids, vol. 72, pp. 127-135, 2017.

[20] M. Moniri, A. Boroumand Moghaddam, S. Azizi et al., "Production and status of bacterial cellulose in biomedical engineering," Nanomaterials, vol. 7, no. 9, p. 257, 2017.

[21] F. Wahid, Y. X. Duan, X. H. Hu et al., "A facile construction of bacterial cellulose/ $\mathrm{ZnO}$ nanocomposite films and their photocatalytic and antibacterial properties," International Journal of Biological Macromolecules, vol. 132, pp. 692-700, 2019.

[22] A. C. Beck, P. Goffredo, I. Hassan et al., "Risk factors for 30day readmission after adrenalectomy," Surgery, vol. 164, no. 4, pp. 766-773, 2018.

[23] A. E. Stoica, C. Chircov, and A. M. Grumezescu, "Nanomaterials for wound dressings: an up-to-date overview," Molecules, vol. 25, no. 11, p. 2699, 2020.

[24] E. Rezvani Ghomi, S. Khalili, S. Nouri Khorasani, R. Esmaeely Neisiany, and S. Ramakrishna, "Wound dressings: current advances and future directions," Journal of Applied Polymer Science, vol. 136, no. 27, p. 47738, 2019.

[25] A. A. Rowe, M. Tajvidi, and D. J. Gardner, "Thermal stability of cellulose nanomaterials and their composites with polyvinyl alcohol PVA," Journal of Thermal Analysis and Calorimetry, vol. 126, no. 3, pp. 1371-1386, 2016.

[26] A. Sivaraman, S. S. Ganti, H. X. Nguyen et al., "Development and evaluation of a polyvinyl alcohol based topical gel," Journal of Drug Delivery Science and Technology, vol. 39, pp. 210-216, 2017.

[27] S. Baghaie, M. T. Khorasani, A. Zarrabi, and J. Moshtaghian, "Wound healing properties of PVA/starch/chitosan hydrogel membranes with nano zinc oxide as antibacterial wound dressing material," Journal of Biomaterials Science, Polymer Edition, vol. 28, no. 18, pp. 2220-2241, 2017.

[28] S. Ullah, A. Ahmad, H. Ri, A. U. Khan, U. A. Khan, and Q. Yuan, "Green synthesis of catalytic zinc oxide nanoflowers and their bacterial infection therapy," Applied Organometallic Chemistry, vol. 34, no. 1, p. e5298, 2020.

[29] S. Shankar and J. W. Rhim, "Effect of Zn salts and hydrolyzing agents on the morphology and antibacterial activity of zinc oxide nanoparticles," Environmental Chemistry Letters, vol. 17, no. 2, pp. 1105-1109, 2019.

[30] D. Bharathi and V. Bhuvaneshwari, "Synthesis of zinc oxide nanoparticles $\mathrm{ZnO}$ NPs using pure bioflavonoid rutin and their biomedical applications: antibacterial, antioxidant and cytotoxic activities," Research on Chemical Intermediates, vol. 45, no. 4, pp. 2065-2078, 2019. 